\title{
Biotechnological

\section{In silico approaches for inhibitor designing against Plasmepsin-II of malarial parasite, Plasmodium malariae}

\author{
Manila Kashyap, Vipan Kumar Sohpal and Parul Mahajan* \\ Department of Chemical Engineering and Biotechnology, Beant College of Engineering and Technology, \\ Gurdaspur-143521, India
}

\begin{abstract}
Plasmodium malariae is one of the causative agents of the deadly disease, malaria. From past few years, investigators have been vigorously involved in searching for an effective cure for this disease. However, the available drugs have not yet proven to be quite efficient in its eradication primarily because of the advanced rate of mutation of the parasite. The present study is directed towards finding an inhibitor against plasmepsin II, one of the aspartic protease encoded by the malarial parasite, which is essential in degrading the host hemoglobin. The structure of the biological target was used to predict candidate drugs that could bind with high affinity and selectivity to the target. The docking behaviour of target protein (2BJU) was studied in order to find out the binding sites for the inhibitor on the protein molecule. The binding pocket that was selected had Phe84 and Thr341 as their active residues, depending upon which few ligand molecules were examined. Subsequently one of the ligand exhibited the best binding properties and the drug likeliness studies were carried out. Based on these studies, it could be inferred that the selected ligand could act as a potential drug candidate and thus, could also be considered for further studies.
\end{abstract}

KEY WORDS: DRUG DESIGNING, HOMOLOGY MODELING, MOLECULAR DOCKING, PLASMEPSIN, RECEPTOR-LIGAND INTERACTIONS

\section{INTRODUCTION}

Malaria has been a deadly disease since the ages of mankind and has been a challenge for the scientific community to produce such a drug that could eradicate the causal organism altogether. It is caused by a parasite
Plasmodium that feeds on human red blood cells and is transferred through the Anopheles mosquito. Malaria is caused by four major species Plasmodium falciparum, $P$. vivax, $P$. malariae and $P$. ovale. Of these $P$. falciparum is responsible for about 95 out of 100 cases Thus, $P$. falciparum becomes the major target for drug intervention. The

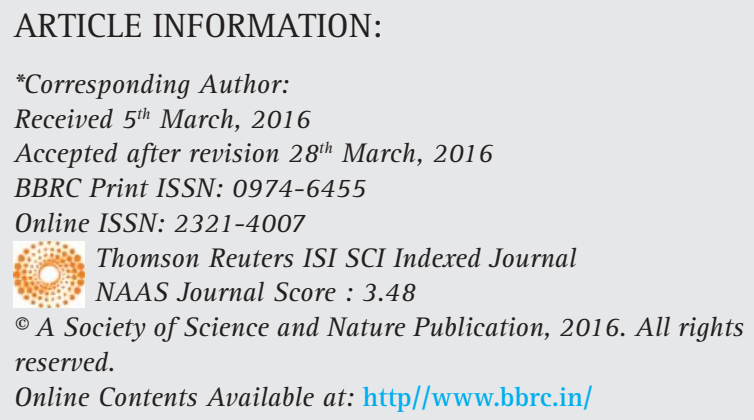


complete genome of this parasite has been sequenced, which has facilitated the investigators to peep into its life cycle and search for potential drug targets, (Oaks 1991, Gil 2011, Mehlin 2005 and Ismail 2016).

This parasite undergoes asexual development in the human erythrocytes or RBCs, during which it utilizes the hemoglobin of RBCs as its food. For this purpose the parasite possesses an array of enzymes that degrade haemoglobin, (Bhaumik 2011). Three major types of enzymes are present in the food vacuole of the parasite-falcipain (cysteine protease) (Rosenthal 1988), falcilysin (metalloprotease) (Eggleson 1999) and plasmepsins (aspartic proteases) (Francis 1994). It is experimentally found that plasmepsins are the enzymes that initiate the process of breakdown of $\mathrm{Hb}$, thereby making these enzymes the potential sites of action of various drugs. In spite of various efforts in this area, it has not been possible to create an appropriate vaccine to prevent malaria. The important drawbacks include (i) the resistance of the vectors (carriers) to the insecticides is increasing (Gulati 2015) and (ii) the emerging varieties of $P$. falciparum are becoming multi-drug resistant (Coombs 2001). Thus the need of the hour is to discover such a drug that has increased selectivity and potency (Na-Bangchang 2009).

Plasmepsin protein has a sequence homology to human related aspartic protease cathepsin D, due to which the enzyme inhibitors discovered so far exhibit selectivity against it (Ersmark 2006). This feature becomes an important issue while designing an appropriate drug, so as to reduce the toxic side effects which may be caused by the inhibitors against pathogenic enzymes (Coombs 2001). Owing to the structural flexibility of the active site of plasmepsin protein, it can harbor different inhibitors scaffolds, presenting a striking impediment for traditional rigid docking procedures. It, therefore poses a daunting task before a researcher to aptly predict the binding mode of the inhibitor with minimum energy and maximum stability ensuring exquisite specificity, (Bhargavi, 2005).

The present study is an attempt to design a highaffinity inhibitor with a broad spectrum towards plasmepsin having least selectivity for human aspartic proteases. The basic aim was to focus on the computer aided drug design against plasmepsin based on the sequencestructure-function relationship, a major challenge in this field. In silico drug designing process involves identification of therapeutic target and building a heterogeneous small molecule library to be tested against it (Wadood 2013). Then virtual screening is initialized by docking of small molecules from the library. These selected hits are checked for specificity by docking at binding sites of known drug targets and then subjected to detail profiling studies and those molecules that pass these studies are termed as leads (Kumar 2013).

\section{MATERIAL AND METHODS}

For in silico drug designing we need 3D structure model of protein. The FASTA sequence of the target plasmepsin of Plasmodium malariae was obtained from protein database of NCBI (Accession Number AAC15794.1 and Gene Id 3095038). The protein consists of 451 amino acids. This sequence serves as input into the BLAST. The level of similarity that exist between protein that have unidentified structures and those that exist within the Protein data bank are shown in BLAST results (Ekenna 2010). Through BLAST we found that the best homolog for plasmepsin II is 2BJU. Its query coverage is $99 \%$ and E-value is 3e-176. The structural summary for the homolog was obtained through PDB.

The structural information obtained from PDB was fed to MODELLER 9v8 and 3D models were obtained. Models were analyzed and verified by Ramachandran plot assessment and Dope (Discrete Optimization Protein Energy) score. Ramachandran plot for each model was viewed via PROCHECK available at SAVES server so as to check the stereo chemical quality of the protein structure generated (Eswar 2007). The 3D structure of protein was visualized using SPDBV. After deduction of structural alignments and comparing their active sites, the stability of structure was increased by shifting amino acids from disallowed to allowed region of Ramachandran plot by loop modelling (Laskowski 1993). Energy minimization of the refined structure was again done by SPBV to find best nearby conformation.

Ligsite was used to identify pockets on protein surfaces suitable for ligand binding. It uses a set of receptorligand complexes to identify small molecule ligand with high precision (Huang 2006) (Hendlich 1997). The potential active site residues found were Phe84 and Thr341. According to the inhibitory site found in the model, the ligands were designed using Ligbuilder 1.2. Seed molecule could be matured in the available binding site after setting up the position of Thr341. In the GROW module of Ligbuilder, number of generations were set to 10 and number of molecules per generation were set by default to 3000. These generated molecules were then filtered through PROCESS module in Ligbuilder and 10 final molecules were selected (Yuan 2011). The next step was to perform rigid docking of the protein molecule and the seed molecule through Hex 9.10 docking software. Docking allows to virtually screen a database of compounds and predict the strongest binders based on various scoring functions. The molecules binding to a receptor would inhibit its function, and thus act as drug (Mathew 2009).

The molecular docking was performed using AUTOD0CK 4.2/ADT18 program. For inhibitory site direction, grid encompassing was used. The Autodock program went through precalculated grids of affınity potentials 


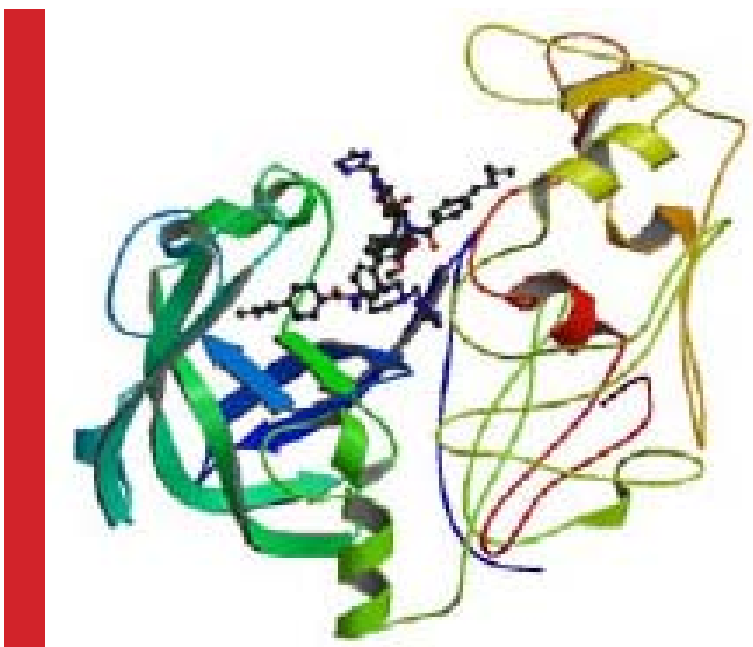

FIGURE 1: Structure of PlasmepsinII homolog (2BJU) with a variety of search algorithms and combined a rapid energy evaluation to find suitable binding positions. The search results were on the basis of the Lamarckian genetic algorithm and for analysis, binding energy was used. Comparison of ligands is made on the basis of binding energy and ligand with minimum binding energy is selected (Ferreira 2015). Molecular properties of the ligands docked were calculated by Molinspiration server and the likeliness of drug was checked by Lipinski's Rule of Five. An ideal drug molecule should be having a molecular weight of less than 500, total number of hydrogen bond should not exceed 5 , miLogP value and should be less than 5 and the sum of $\mathrm{N}$ and 0 should not be more than 10, (Narayanaswamy 2013).

\section{RESULTS AND DISCUSSION}

The 3D structure of homolog for plasmepsinII (2BJU) was visualised (Figure I) and files were aligned with the

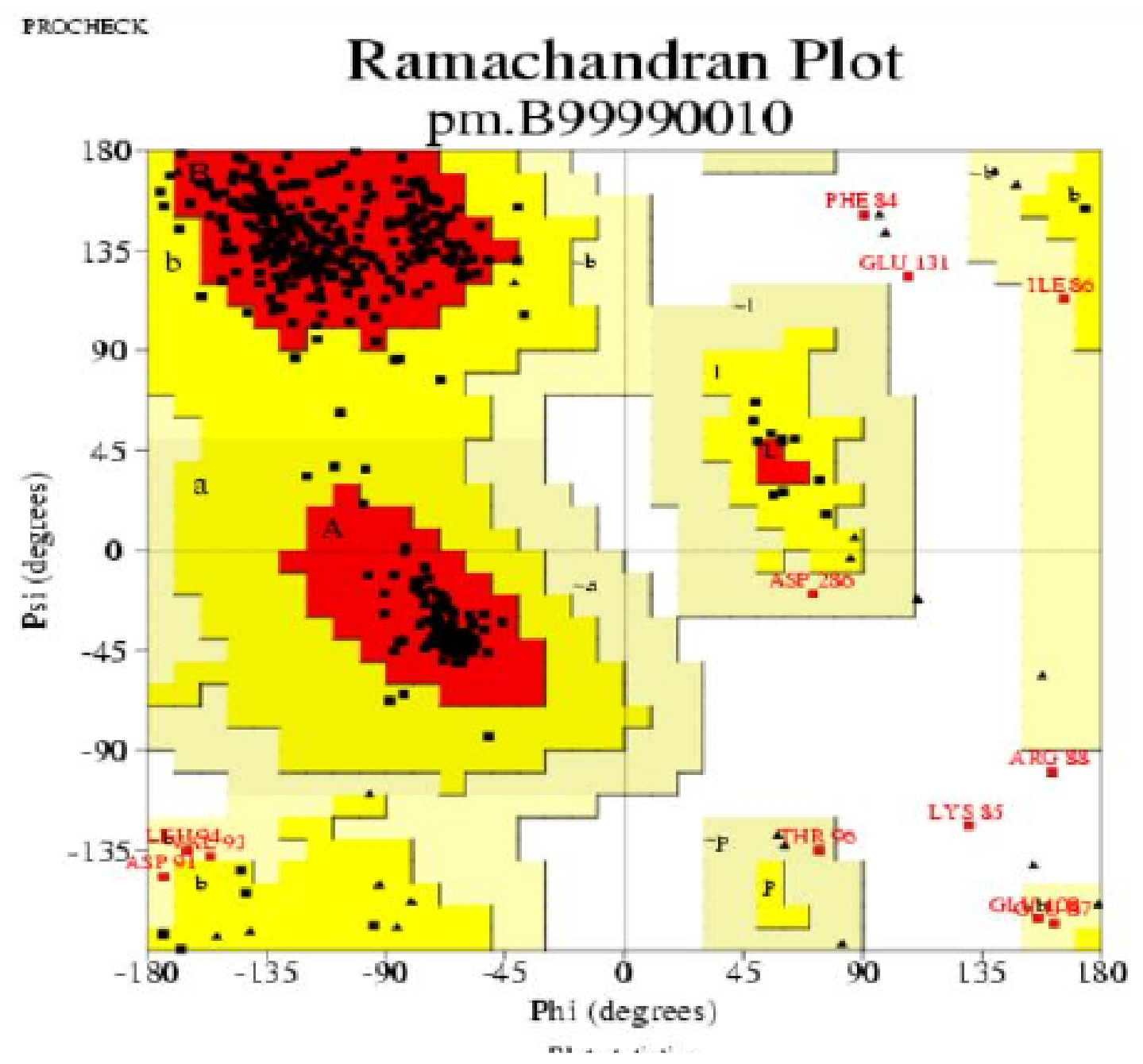

FIGURE 2: Ramachandran Plot analysis of selected model 


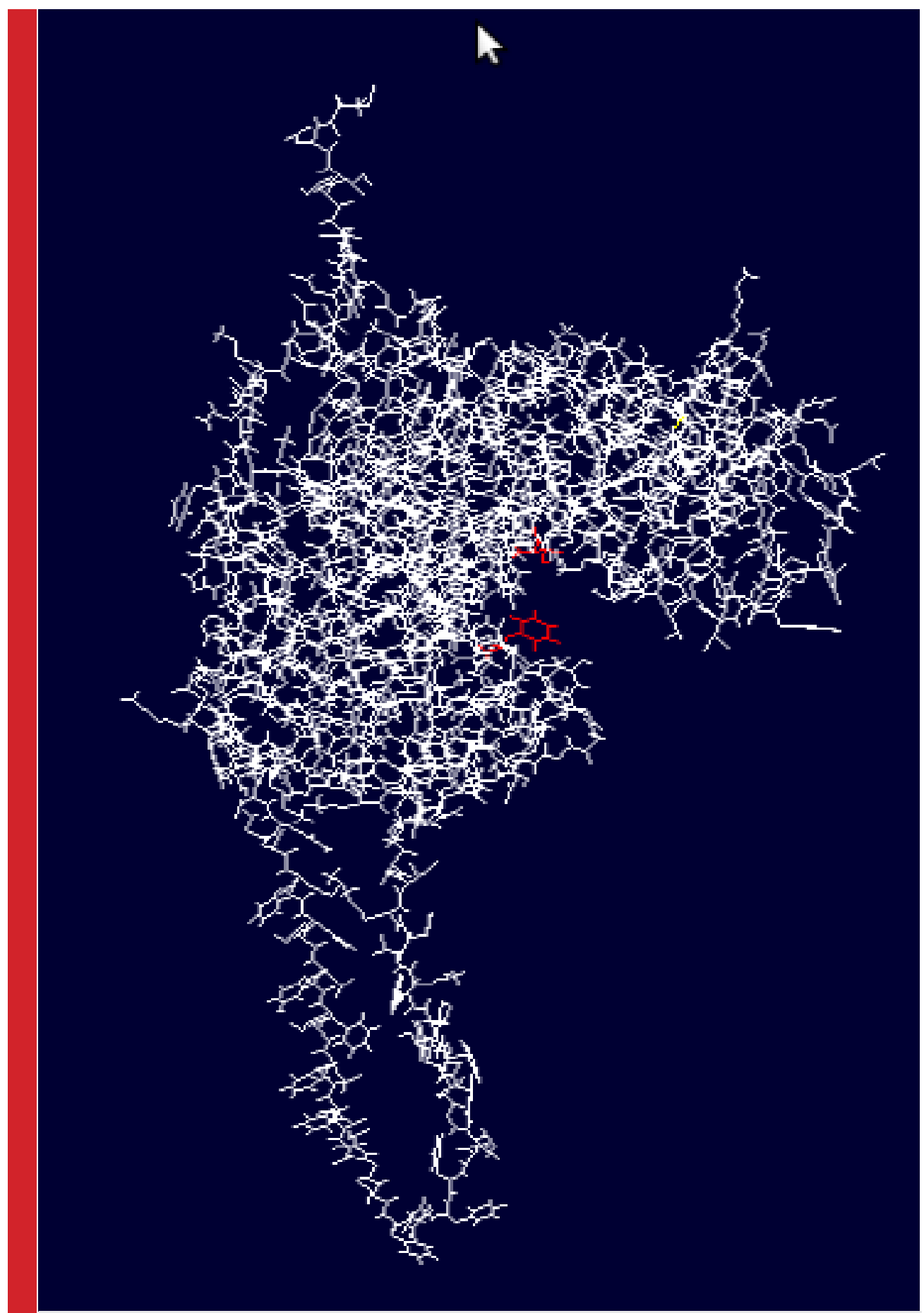

FIGURE 3: Protein structure showing active site residues (Phe84 and Thr341)

target by MODELLER- which predicts the 3D structure of unknown proteins by satisfaction of spatial restraints. 3D models were then analysed and verified on the basis of Ramachandran plot which was viewed via Procheck (Figure II). The output of PROCHECK evaluated the various aspects of the model's quality (Ramesh 2012). Ram- achandran plot assesses the possible conformation of $\varphi$ and $\psi$ angles for a polypeptide in order to find the stable conformations. The best model had following parameters: 88.4 core, 8.6 allowed, 2.0 generously allowed, 1.0 disallowed. SPDBV was then used for model refinement which was done by loop modelling and energy mini- 


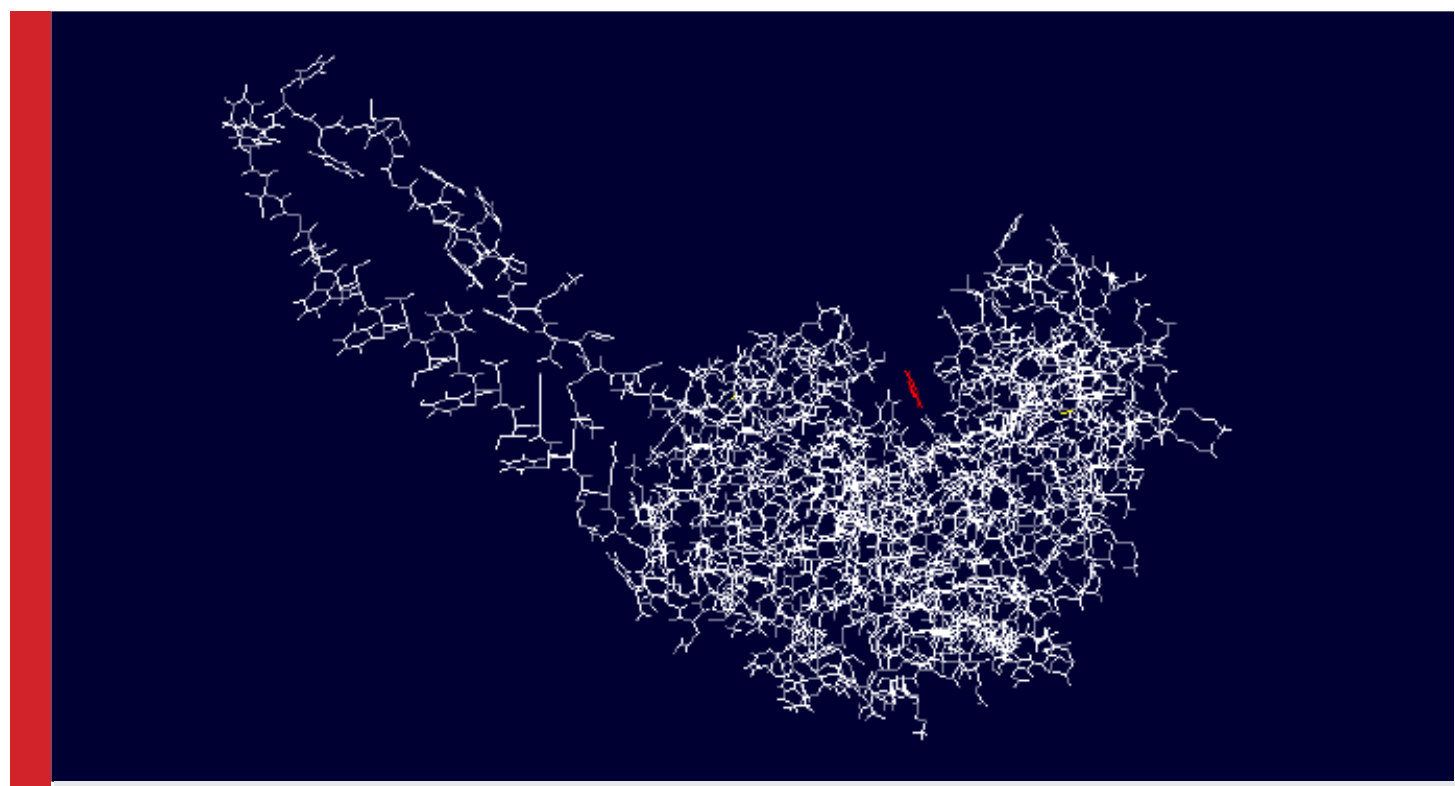

FIGURE 4: Ligand positioned in the active site of the protein (shown in red).

Table I: Chemical criteria used for PROCESS module in LigBuilder

\begin{tabular}{|l|l|}
\hline Property & Value \\
\hline Maximal molecular weight & 500 \\
\hline Minimal molecular weight & 250 \\
\hline Maximal logP & 6.00 \\
\hline Minimal logP & 3.00 \\
\hline Maximal pKd & 10.00 \\
\hline Minimal pKd & 5.00 \\
\hline Number of output molecules & 10 \\
\hline
\end{tabular}

mization, thereby increasing the stability of the protein structure.

This protein structure was then analysed so as to find binding pockets through Ligsite. Ligsite, by default generates three pockets/active site for ligand binding, out of which one with the residues Phe84 and Thr341 was selected (Figure III). These active residues were checked for ligand binding through rigid docking via Hex-interactive protein docking and molecular superposition program (Figure IV).Based on the 3D dimensional structure of the target protein, ligand molecules were build and screened within the binding pocket by Ligbuilder (Table I).

In order to obtain better binders, Autodock was performed with a ligand file and final structure file. The

Table II: Molecular properties of ligand molecules by MolInspiration

\begin{tabular}{|c|c|c|c|c|c|c|c|c|c|}
\hline Ligand & miLogPa & TPSA $^{b}$ & natoms $^{c}$ & $\mathrm{MW}^{\mathrm{d}}$ & $\mathrm{nON}^{\mathrm{e}}$ & $\mathrm{nOHNH}^{\mathrm{f}}$ & nviolatations ${ }^{\mathrm{g}}$ & nrotb $^{\mathrm{h}}$ & volume $^{\mathrm{i}}$ \\
\hline 1. & 5.035 & 100.75 & 29.0 & 392.50 & 5 & 3 & 1 & 10 & 379.948 \\
\hline 2. & 4.373 & 113.83 & 30 & 397.35 & 7 & 6 & 1 & 12 & 398.086 \\
\hline 3. & 4.415 & 109.68 & 30 & 395.68 & 6 & 6 & 1 & 11 & 392.456 \\
\hline 4. & 4.124 & 132.68 & 32 & 509.24 & 4 & 2 & 1 & 11 & 464.257 \\
\hline 5. & 4.855 & 123.47 & 31 & 502.49 & 6 & 5 & 1 & 13 & 432.876 \\
\hline 6. & 5.137 & 92.56 & 28 & 378.68 & 8 & 6 & 2 & 10 & 345.763 \\
\hline 7. & 4.690 & 146.45 & 35 & 517.56 & 6 & 4 & 2 & 9 & 487.479 \\
\hline 8. & 4.912 & 183.47 & 27 & 363.36 & 11 & 7 & 2 & 7 & 369.356 \\
\hline 9. & 4.784 & 92.06 & 33 & 513.46 & 5 & 2 & 1 & 12 & 422.786 \\
\hline 10. & 5.273 & 78.57 & 25 & 322.45 & 4 & 2 & 1 & 13 & 310.576 \\
\hline
\end{tabular}

${ }^{a}$ Octanol-Water partition coefficient, ${ }^{\mathrm{b} P o l a r}$ surface area, ${ }^{\mathrm{N}}$ Number of non hydrogen atoms, ${ }^{\mathrm{d}}$ Molecular weight, ${ }^{\mathrm{e}} \mathrm{Number}$ of hydrogen, bond

acceptors [ 0 and $\mathrm{N}$ atoms], ${ }^{\mathrm{f}} \mathrm{Number}$ of hydrogen bond donors [OH and $\mathrm{NH}$ groups], sNumber of Rule of 5 violations, humber of rotatable bonds Et i Molecular volume (selected ligand shown in bold). 


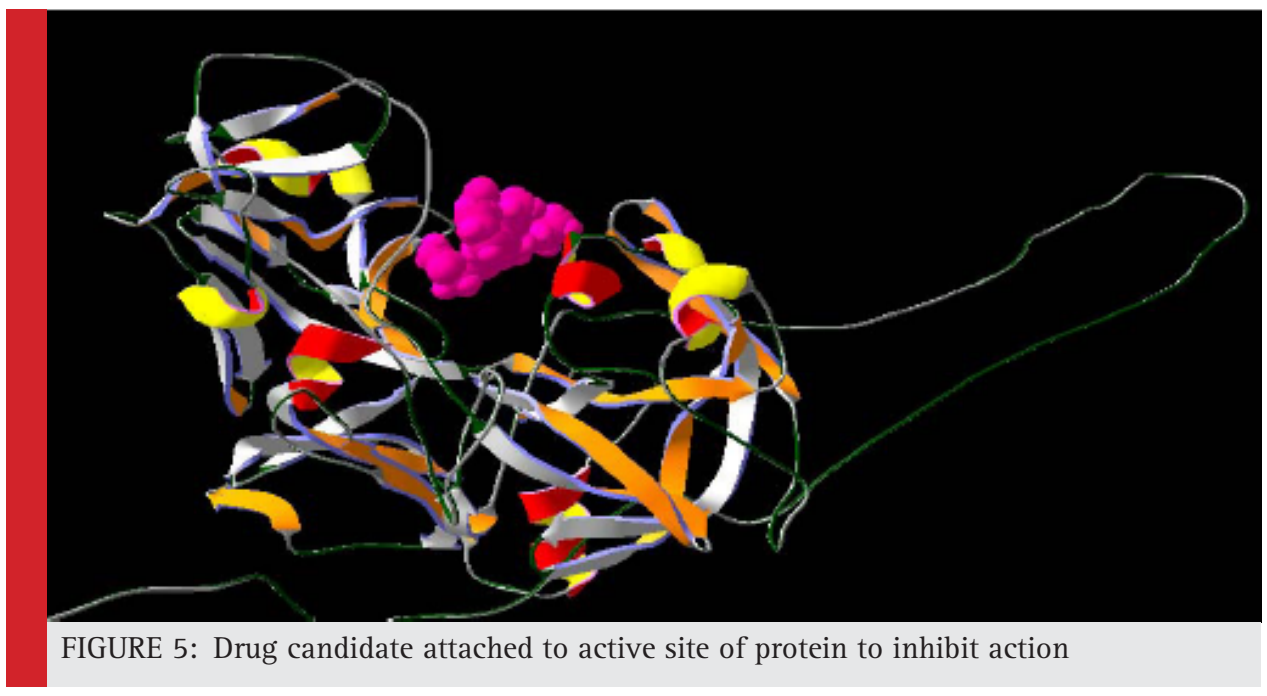

most important properties for a compound to become a successful drug are molecular physicochemical and drug-likeness. Lipinski's rule is therefore used to optimize the active lead structure obtained (Lipinski 2001 and Megantara 2016).

According to Lipinski's rule, an ideal drug candidate must possess the following characteristics: $\log \mathrm{P} \leq 5$; Molecular weight (MW) $\leq 500 \mathrm{~g} / \mathrm{mol}$; Number of hydrogen bond acceptors (HBA) (sumof $\mathrm{N}$ and 0 atoms) $\leq 10$, Number of hydrogen bond donors (HBD) (sum of $\mathrm{OH}$ and $\mathrm{NH}$ groups) $\leq 5$; Number of rotatable bonds (nRotb) $\leq$ 10 (Araújo de Brito 2011) (Table II). Ligand having most favourable properties was selected as the main target compound. The SMILES notation (as obtained from molinspiration) for the selected compound are original SMILES $\mathrm{c} 1(\operatorname{cc}(\operatorname{cc}(\mathrm{c} 1) / \mathrm{C})=\mathrm{C} / \mathrm{C}) \mathrm{c} 1 \mathrm{c}(\operatorname{cccc} 1) \mathrm{C}(=[0])[0]) \mathrm{C}(\mathrm{C}(\mathrm{N})=[0])$ $[\mathrm{NH}] \mathrm{CCCCCC}$ and $\mathrm{mi}$ SMILES CCCCCCc2cc(C[NH]) $\mathrm{C}(\mathrm{N})=0) \operatorname{cc}(/ \mathrm{C}(=\mathrm{C} / \mathrm{C}) \operatorname{c1} \operatorname{cccc} 1 \mathrm{C}([0]=0) \mathrm{c} 2$ (Figure V).

The current study was focused on designing an inhibitor against plasmepsinII through the process of homology modelling. The dynamic models of compounds can be build by computer aided modelling (Pugazhendhi 2013) which also allows molecular visualization and demonstration of chemical principles. The interactions between molecular structures (generated computationally) are quite complex mainly because of the involvement of intermolecular bonding (hydrophobic, dispersion, or van der Waals force, electrostatic and hydrogen bonding) (Oliveira 2013). Ligand designed in this study could therefore be used as a potential drug candidate against the desired protein.

\section{CONCLUSION}

Computational approaches for the prediction and analyses of drug targets have proved to be highly success- ful in the field of drug designing and development. It also helped us to understand the molecular nature and functions of various proteins. The results obtained from above approaches are not absolute but still provides us with sufficient details so as to deal with the various diseases affecting humankind.

\section{ACKNOWLEDGEMENT}

The authors would like to thank IBI Biosolutions Pvt. Ltd., Panchkula-134109, India for providing workspace for this project.

\section{REFERENCES}

Araújo de Brito, M., (2011) Pharmacokinetic study with computational tools in the medicinal chemistry course. Brazilian Journal of Pharmaceutical Sciences, Vol. 47, pp. 798-805.

Bhargavi, R., Sastry, G.M., Murty, U.S., Sastry, G. N., (2005) Structural and active site analysis of plasmepsins of Plasmodium falciparum: potential anti-malarial targets. International Journal of Biological Macromolecules, Vol. 37, pp. 73-84.

Bhaumik, P., Horimoto, Y., Xiao, H., Miura, T., Hidaka, K., Kiso, Y., Wlodawer, A., Yada, R.Y., Gustchina, A., (2011) Crystal structures of the free and inhibited forms of plasmepsin I (PMI) from Plasmodium falciparum. Journal of Structural Biology, Vol 175, pp 73-84.

Coombs, G.H., Goldberg, D.E., Klemba, Berry, M.,C., Kay, J., Mottram, J.C., (2001) Aspartic proteases of Plasmodium falciparum and other parasitic protozoa as drug targets. Trends in Parasitology, Vol. 17(11), pp. 532-537.

Eggleson, K.K., Duffin, K.L., Goldberg, D.E., (1999) Identification and characterization of falcilysin, a metallopeptidase involved in hemoglobin catabolism within the malaria parasite Plasmodium falciparum. J. Biol. Chem, Vol 274, pp 3241132417. 
Ekenna, C., Fatumo, S., Adebiyi, E., (2010) In-silico evaluation of malaria drug targets. International Journal of Engineering and Technology, Vol.2(2), pp. 132-135.

Ersmark, K., Samuelsson, B., Hallberg, A., (2006) Plasmepsins as potential targets for new antimalarial therapy. Medicinal Research Reviews, Vol. 26(5), pp. 626-666.

Eswar, N., Webb, B., Marti-Renom, M.A., Madhusudhan, M.S., Eramian, D., Shen, M.Y., Pieper, U., Sali, A., (2007) Comparative protein structure modeling using MODELLER. Curr Protoc Bioinformatics, Chapter 2:Unit 2.9.

Ferreira, L.G., Santos, R.N., Oliva, G., Andricopulo, A.D., (2015) Molecular Docking and Structure-Based Drug Design Strategies. Molecules, Vol.20, pp. 13384-13421.

Francis, S.E., Gluzman, I.Y., Oksman, A., Knickerbocker, A., Mueller, R., Bryant, M., Sherman, D.R., Russell, D.G., Goldberg, D.E., (1994) Molecular characterization and inhibition of Plasmodium falciparum aspartic hemogloinase. EMBO J, Vol 13, pp 306-317.

Gil, L., Alejandro, Valiente, Pedro A., Pascutti, Pedro, G., Pons, Tirso., (2011) Computational Perspectives into Plasmepsins Structure-Function Relationship: Implications to Inhibitors Design. Journal of Tropical Medicine, Vol 2011, pp 1-15

Gulati, M., , Narula, A., Vishnu, R., Katyal, G., Negi, A., Ajaz, I., Narula, K., Chauhan, G., Kant, R., Lumb, V., Babbar, S., Wadehra, N.R., Bhaskar, D., (2015) Plasmepsin II as a Potential Drug Target for Resistant Malaria. DU Journal of Undergraduate Research and Innovation, Vol 1(3), pp 85-95.

Hendlich, M., Rippmann, F., Barnickel, G., (1997) LIGSITE: automatic and efficient detection of potential small moleculebinding sites in proteins. Journal of Molecular Graphics and Modelling, Vol.15(6) pp.359-363.

Huang, B., Schroeder, M., (2006) LIGSITE ${ }^{c s}$ : predicting ligand binding sites using the connolly surface and degree of conservation. BMC Structural Biology, vol.6(19).

Ismail, H.M., Barton, V., Phanchana, M., Charoensutthivarakul, S., Wong, M.H.L., Hemingway, J., Biagini, G.A., O'Neill, P.M., Ward, S.A., (2016) Artemisinin activity-based probes identify multiple molecular targets within the asexual stage of the malaria parasites Plasmodium falciparum 3D7. PNAS, Vol 113(8), pp. 2080-2085.

Kumar S. And Chethan H (2013) An Insight to Drug Designing by In Silico approach in Biomedical Research. J Pub Health Med Res. Vol 1(2), pp.63-66.

Laskowski., MacArthur, M.W., Moss, D.S., and Thornton, J.M., (1993) PROCHECK: a program to check the stereochemical quality of protein structures. J. Appl. Cryst. Vol (26), pp. 283291.

Lipinski, C. A., Lombardo, F., Dominy, B. W., Feeney, P. J., (2001) Experimental and computational approaches to estimate solubility and permeability in drug discovery and development settings. Adv. Drug Deliv. Rev., Vol 46, pp.3-26.
Mathew, J.A., Raj, N.N., (2009) Docking Studies on Anticancer Drugs for Breast Cancer Using Hex. International MultiConference of Engineers and Computer Scientists, Vol.1.

Megantara, S., Immaculata Iwo, M., Levita, J., Ibrahim, S., (2016) Determination of ligand position in aspartic proteases by correlating tanimoto coeffıcient and binding affınity with root mean square deviation. Journal of Applied Pharmaceutical Science Vol 6(01), pp. 125-129.

Mehlin, Christopher (2005) Structure-Based Drug Discovery for Plasmodium falciparum. Combinatorial Chemistry \& High Throughput Screening, Vol 8, pp 5-14.

Na-Bangchang, K., Karbwang, J., (2009) Current status of malaria chemotherapy and the role of pharmacology in antimalarial drug research and development. Fundamental and Clinical Pharmacology, Vol. 23(4), pp. 387-409.

Narayanaswamy, R., Lam Kok Wai, L.K., Ismail, I.S., (2013) Molecular docking analysis of natural compounds as Human neutrophil elastase (HNE) inhibitors. Journal of Chemical and Pharmaceutical Research, Vol.5(10), pp 337-341.

Oaks, S.C., Mitchell, V.S., Jr, Pearson, G.W., Carpenter, C.C.J., eds (1991) Malaria: Obstacles and Opportunities. A report of the committee for the study on malaria prevention and control: Status review and alternate strategies. Division of International Health, Institute of Medicine, National Academy, Washington, DC.

Oliveira, M.E., Cenzi, G., Nunes, R.R., Andrighetti, C.R., Valadão, D.M., Reis, C., Simões, C.M., Nunes, R.J., Júnior, M.C., Taranto, A.G., Sanchez, B.A.M., Viana, G.H.R., Varotti, F., (2013) Antimalarial Activity of 4-Metoxychalcones: Docking Studies as Falcipain/Plasmepsin Inhibitors, ADMET and Lipophilic Efficiency Analysis to Identify a Putative Oral Lead Candidate. Molecules, Vol 18, pp 15276-15287.

Pugazhendhi, D., Umamaheswari, T.S., (2013) Insilico Methods in Drug Discovery - A Review. International Journal of Advanced Research in Computer Science and Software Engineering. Vol 3 (5), pp 680-683.

Ramesh KD., M, Sanjuktha., R, Singaravel., S, Ramakrishnan., J.J.S, Rajan., K.S, Satheesh, M., Poornima, T.C, Santiago, S.V., Alavandi. (2012) Molecular modelling and Docking studies on shrimp vitellogenin receptor and ligand target mediated delivery system. International Journal of Research in Drug Delivery. Vol 2(1), pp 11-14

Rosenthal, P.J., McKerrow, J.H., Aikawa, M., Nagasawa, H., Leech, J.H., (1988) A malarial cysteine proteinase is necessary for hemoglobin degradation by Plasmodium falciparum. J. Clin. Invest, vol 82, pp 1560-1566.

Wadood, A., Ahmed, N., Shah, L., Ahmad, A., Hassan, H., Shams, S., (2013) In-silico drug design: An approach which revolutionarised the drug discovery process. OA Drug Design Et Delivery, Vol 1(1):3.

Yuan, Y., Pei, J., Lai, L., (2011) LigBuilder 2: A Practical de Novo Drug Design Approach. Journal of Chemical Information and Modeling, Vol.51, pp. 1083-1091. 